\title{
JOSÉ DE ALENCAR: INSIGHTS SOBRE A ACOMODAÇÃO TENSA ENTRE TRADIÇÃO E MODERNIDADE NO BRASIL
}

\author{
Márcio Luiz do NASCIMENTO* \\ Renato Somberg PFEFFER ** \\ Carolina Portugal Gonçalves da MOTTA ${ }^{* * *}$ \\ Ana Luiza Gomes de ARAÚUO****
}

RESUMO: O presente trabalho analisa a acomodação eivada de tensões entre o fenômeno patrimonialista e o modelo burocrático-capitalista no final do século XIX no Brasil a partir de insights contidos na obra Senhora (1875) de José de Alencar. Em um primeiro momento, o artigo analisa as interpretações do Brasil sob a ótica weberiana para, em seguida, discutir o processo de acomodação entre tradição e modernidade no contexto histórico do Império brasileiro contidos nessa obra do romancista. A hipótese que norteia o texto assenta-se na ideia de que o patrimonialismo, presente no Brasil desde o período colonial, atingiu o ápice de sua influência e um elaborado processo de acomodação com a ordem racional-legal durante o Império. José de Alencar retrataria nos personagens e no enredo da referida obra os elementos dessa acomodação e sua oposição ao avanço da ordem burguesa sobre a ordem patrimonialista.

PALAVRAS CHAVE: Jose de Alencar. Patrimonialismo. Modelo burocráticocapitalista. Acomodação.

\footnotetext{
* UEMG - Universidade do Estado de Minas Gerais. Belo Horizonte - MG - Brasil. 38.200-000 mrc.Iz.nascimento@gmail.com. https://orcid.org/0000-0002-1667-630X.

** FJP - Fundação João Pinheiro de Minas Gerais. Diretoria de Políticas Públicas. Belo Horizonte - MG Brasil. 31.275-150 - renato.pfeffer@fjp.mg.gov.br. https://orcid.org/0000-0003-2633-8694.

*** FJP - Fundação João Pinheiro de Minas Gerais. Escola de Governo. Belo Horizonte - MG - Brasil. 30.140-001 - carolina.portugal@fjp.mg.gov.br. https://orcid.org/0000-0003-1081-991X.

**** FJP - Fundação João Pinheiro de Minas Gerais. Escola de Governo. Belo Horizonte - MG - Brasil. 30.140-001 - ana.araujo@fjp.mg.gov.br. https://orcid.org/0000-0003-4954-1628.
} 
Introdução

O Brasil do século XIX foi marcado por fatos históricos relevantes como a abolição da escravidão (1888), a proclamação da República (1889), a ascensão de uma classe burguesa vinculada, principalmente, à produção de café e por intensos debates literários e sociopolíticos protagonizados por grandes expoentes intelectuais. Estes fatores, dentre outros, levaram a uma acomodação eivada de tensões entre o modelo de organização político-social patrimonialista predominante no país e o modelo burocrático-capitalista.

A contribuição da sociologia para a compreensibilidade da literatura brasileira no século XIX escora-se, centralmente, na relação entre textos literários e contexto sociopolítico do Brasil Império. No Brasil da segunda metade do século XIX era ainda incipiente o processo de formação das esferas culturais, logo, os campos intelectuais e políticos não estavam autonomizados, mas, antes, estavam fortemente imbricados. De tal modo, que nenhum dos letrados, a exemplo de Machado de Assis, José de Alencar, Silvio Romero, Joaquim Manuel de Macedo, Castro Alves, Franklin Távora, Manuel Antônio de Almeida, dentre outros, podia dedicar-se unicamente à literatura ou por meio dela manter-se financeiramente.

Os intelectuais estavam inseridos numa sociedade de estrutura estamental patrimonialista cujos reflexos atuavam no sentido de retardar e obstruir a construção e consolidação do campo literário e intelectual no Brasil. Assim, por um lado, os espaços institucionais voltados à edificação, celebração e reprodução das carreiras intelectuais, usualmente presentes na cultura Ocidental, ou eram inexistentes (universidades e centros de pesquisa), precários (editoras, gráficas e livrarias) ou, quando existentes, eram espaços de desdobramentos, simultâneos, de carreiras intelectuais e políticas (Faculdades Imperiais, Escolas de Ensino Superior, Museus, bibliotecas e editoras públicas).

De outro lado, observam-se os reflexos da criação de algumas condições indispensáveis ao desenvolvimento da cultura e das letras no Brasil Império, iniciadas entre 1810 e 1830, porém mais perceptíveis na segunda metade do século XIX. Neste sentido, elenca-se a criação da Biblioteca Real (1808) e da Impressão Régia (1810); a inauguração das Faculdades de Direito de Olinda e de São Paulo (1827); o desenvolvimento da imprensa periódica e de livros, tais como a Gazeta do Rio de Janeiro (1808), Correio Brasiliense (1808-1822), Aurora Fluminense (1827); Anais Fluminenses de Ciências, Artes e Literatura (1822); o Jornal Cientifico, Econômico e Literário (1826); o Spectador Brasileiro e o Jornal do Commercio.

A par das transformações operadas na esfera cultural nacional, ainda que 
incipientes, observa Werneck Sodré (1964), pela primeira vez, um escritor brasileiro alcançou a publicação inédita da segunda edição de um romance: A Moreninha, em 1846, de Joaquim Manuel de Macedo ( $1^{\text {a }}$ edição publicada em 1845).

Por sua vez, em razão do adensamento da vida literária brasileira, a especialização se impôs aos letrados brasileiros, após 1860, por meio da exigência de se dedicarem a um único gênero literário. Condição até então desconhecida dos intelectuais brasileiros, que cultivavam, simultaneamente, vários gêneros literários: poesia, prosa, teatro, florilégios, biografias, histórias de vida etc.

O processo de criação de algumas das condições estruturais para a formação do campo intelectual e literário no Brasil Império é indissociável do efetivo fortalecimento dos grupos urbanos, em particular dos indivíduos ligados às profissões liberais. $\mathrm{Na}$ medida em que o meio social tornava-se menos rarefeito, consolida-se um público leitor mais amplo e as narrativas dos romances são adensadas.

A leitura do romance Senhora (1875), circunscrita e tensionada pelo contexto de crise sociopolítica e econômico-institucional do Brasil Império, revela, descortina e recupera os elementos centrais para desvelar o Brasil da segunda metade do século XIX.

Estes elementos podem ser colocados nos seguintes termos (SCHWARZ, 2000): o gênero romance produzido no Brasil até a publicação do romance Senhora de José de Alencar reconstituía alguns aspectos da realidade urbana nacional por meio da construção de personagens romanceadas, que eram transplantadas da realidade para o interior da trama com os seus hábitos, gostos, profissões e ocupações. Todavia, o universo narrativo elaborado atenuava ou encobria os conflitos sociais entre livres e escravos, entre poucos ricos e muitos homens pobres livres. Os indivíduos ficcionais não eram dilacerados pelo remorso e a solidão, a pobreza e a marginalização social, desconheciam o drama do homem urbano do Brasil do século XIX, bem como de tantos outros indivíduos desejosos de mobilidade social, porém obstruídos politicamente do establishement Imperial.

José de Alencar, por sua vez, no romance Senhora, adensa a trama ao construíla tensionada pela presença de vários grupos sociais urbanos, contudo, alinha-se, numa clara posição de defesa do seu status quo, à concepção do universo ficcional romântico como momento necessário de introdução de uma eticidade substancial, bastante integradora e ordenadora para unir consciência e atitudes, moral e política, modernização e tradição.

Diante da ordem social e política cada vez mais complexa, que deslocava a possibilidade de manutenção da ordem, a continuidade da monarquia imperial e o status da elite agraria nacional, José de Alencar no romance Senhora sustenta a defesa do projeto nacionalista romântico que naturalizou a tradição-memória nacional como fato 
positivo, evidente, inelutável e necessário à legitimação da história, da vida políticoeconômica e como o pressuposto à introdução de qualquer técnica e doutrina sociopolítica transformadora.

\section{Interpretações weberianas do Brasil}

O pensamento weberiano no Brasil tem sido utilizado para explicar o atraso da sociedade brasileira, ou seja, sua teoria é utilizada para diagnosticar os motivos que impedem a superação do patrimonialismo ibérico rumo à modernidade. No entanto, os intérpretes que utilizam o modelo weberiano, para analisar a singularidade social do país, possuem posições bastante controversas acerca da relação entre Estado e sociedade e do peso conferido a cada um desses polos, bem como, há muitas divergências interpretativas da maior ou menor disjunção entre elas. Estes aspectos podem ser analisados a partir de duas grandes vertentes segundo Vianna (1999): a institucionalista ou de Estado (FAORO, 1975; SCHWARTZMAN, 1998) e a societal (FERNANDES, 1975; FRANCO, 1997).

A visão de Faoro (1975) e de Schwartzman (1998), hegemônicas no pensamento social brasileiro (VIANNA, 1999), relaciona o atraso brasileiro com a herança patrimonial do Estado português, cujo reforço se deu com a transferência da corte portuguesa para o Brasil no século XIX. O legado português representou a autonomia do Estado em relação à sociedade civil reprimindo os interesses privados e comprometendo o avanço de uma racionalidade fundada na legalidade. Essa visão ainda afirma que a ausência do feudalismo no Brasil aproxima o país da tradição política do Oriente marcado pela inexistência de fronteiras nítidas entre a esfera pública e a privada. Aproximando o patrimonialismo ibérico do despotismo Oriental, Faoro (1975) sugere que o capitalismo e a integração entre sociedade e Estado só teriam se consolidado em países que vivenciaram o feudalismo. Nesse sentido, o Brasil não seria um caso Ocidental, pois o Estado, por ter antecedido os grupos de interesses, possuiria objetivos próprios voltados para seus dirigentes e, por sua vez, o bem público seria encarado como bem a ser explorado em benefício próprio. A consequência disso seria a formação de um sistema político de cooptação, a consolidação de uma sociedade de tipo estamental e a sedimentação de uma organização e administração estatal que se sobrepunha à estrutura política representativa, à estrutura social de classes e à sociedade civil, respectivamente. Em essência, corresponderia ao domínio patrimonial-burocrático frente ao cidadão limitado de seus direitos civis, sociais e políticos.

Nessa visão, o capitalismo brasileiro possuiria uma patologia estrutural que 
obstruiria o acesso ao moderno. Isso resultaria numa modernização marcada pelo não rompimento e pela reprodução do passado patrimonial, na medida em que as elites detêm o controle político das mudanças sociais. Esse Estado "neopatrimonial" (SCHWARTZMAN, 1998, p.45) preservaria as desigualdades do país por meio de práticas de cooptação e de restrição da livre manifestação de interesses, sendo ele "uma forma bastante atual de dominação política por um 'estrato social sem propriedades e que não tem honra social por mérito próprio', ou seja, pela burocracia e a chamada classe política" (SCHWARTZMAN, 1998, p.45-46).

Nessa perspectiva, o rompimento com o Oriente político só poderia ocorrer com uma reforma política que permitisse à sociedade civil manifestar seus interesses sem qualquer forma de tutela estatal. Por ser uma marca do Estado e não da sociedade, o patrimonialismo brasileiro só poderia ser superado pela reforma política e não pela reforma social. As principais controvérsias na interpretação weberiana do patrimonialismo brasileiro derivam, justamente, desse eixo explicativo: de um lado a visão predominante daqueles que advogam a tese da reforma político-legal como origem da modernização da sociedade brasileira, de outro, os que defendem o inverso.

Como contraponto da concepção dominante da interpretação weberiana do patrimonialismo no Brasil, encontram-se análises que apontam para o compromisso estabelecido, desde a independência, entre a ordem racional-legal e a patrimonial, entre o liberalismo político e a estrutura social escravista, entre a representação e a cooptação. Nessa visão alternativa, a questão da ruptura com a ordem patrimonial deveria se originar nas relações sociais de padrão patrimonial, e não no Estado. Seria, portanto, necessário romper as condutas sociais marcadas pela dominação pessoal que impediriam a vigência da orientação racional (FRANCO, 1997). Sob essa perspectiva, não bastaria uma reforma política para alterar a ordem patrimonial, pois essa só ocorreria no longo prazo e teria origem na própria sociedade.

Enquanto o patrimonialismo institucional (FAORO, 1975; SCHWARTZMAN, 1998) concede ao Estado uma autonomia relativa de seus estamentos em relação à sociedade, forjando uma dominação de cima para baixo, o patrimonialismo societário (FERNANDES, 1975; FRANCO, 1997) propõe uma acomodação na sociedade brasileira entre tradição e modernidade eivada de tensões refletidas no Estado. Essa "unidade contraditória" que teria sido "determinada na gênese do sistema colonial, sustentou, com suas ambiguidades e tensões, a maior parte da história brasileira" (FRANCO, 1997, p.11). A relação entre tradição e modernidade, portanto, não seria disjuntiva, pois a dinâmica social reverberaria na esfera política e seria por essa afetada, em um processo dialético. Na versão do patrimonialismo societal, o Brasil seria encarado como parte da história do Ocidente incluído de forma tardia e ambígua, e não 
em uma visão Oriental como proposta pelo patrimonialismo de Estado. Essa ambiguidade tem como representação máxima a arquitetura liberal do Estado moderno que convive com a organização social patrimonial e a escravidão.

Entre os representantes dessa vertente do patrimonialismo societal, se destacam os trabalhos de Florestan Fernandes (1975) e Maria Sílvia de Carvalho Franco (1997). Ambos destacam que a causa do atraso brasileiro estaria no campo das relações sociais patrimoniais e de sua influência sobre o Estado e não o inverso, numa clara influência de um dos pioneiros da utilização do conceito de patrimonialismo no Brasil, Sérgio Buarque de Holanda (1976). Holanda (1976) aponta para os modos de socialização do brasileiro oriundos da península ibérica no trato interpessoal, entre eles, o subjetivismo, a afetividade, a simpatia, a plasticidade. Essas características, antitéticas com a racionalidade capitalista apontada por Weber, teriam sido transpostas para a estrutura do Estado brasileiro. Disso resulta um serviço público personalista e que concede privilégios com base na simpatia. A percepção culturalista de Holanda (1976) pode ser melhor entendida por meio de seu conceito de homem cordial. A cordialidade, à qual o pensador se refere, relaciona-se à ideia de que as ações do brasileiro, em especial no campo da política, são pautadas pela subjetividade e sentimentos. Ele não consegue diferenciar a gestão da família e a gestão da coisa pública, pois falta-lhes a objetividade exigida pela burocracia. $\mathrm{O}$ resultado dessa não distinção entre patrimônio público e privado é a presença de funcionários patrimoniais ao invés de burocratas.

Embora complementares na sua análise, Couto (2016) aponta uma distinção entre patriarcalismo e patrimonialismo na obra de Holanda (1976). O patriarcalismo, marcado pelo poder do patriarca, submete sua família, seus escravos e seus agregados à sua vontade, de forma incondicional. O patrimonialismo, por sua vez, seria a não separação entre o privado e o público, que impediria a emersão da ordenação impessoal do Estado. Ambos são heranças ibéricas que obstruem a distinção entre o domínio familiar e o da administração pública. Ou seja, os contatos primários do núcleo familiar, os laços de sangue, estariam sempre acima dos interesses da nação. O patrimonialismo na administração pública, portanto, seria derivado do patriarcalismo ${ }^{1}$.

Assim como Holanda (1976), Fernandes (1975) enfatiza a influência patrimonial da sociedade brasileira sobre o Estado, porém sob uma perspectiva diferente da culturalista, ao destacar como a ideologia liberal foi internalizada no final do período colonial brasileiro de forma bastante particular. Ela não expressava um desejo de

\footnotetext{
${ }^{1}$ Diferentemente de Holanda, Faoro, "provavelmente temendo que a descentralização comprometa a noção de patrimonialismo e caracterize a de feudalismo, prioriza a proeminência do centralismo na tradição política brasileira" (CAMPANTE, 2003, p.160).
} 
emancipação nacional, ao contrário, representava a vontade de emancipação dos estamentos senhoriais da "tutela colonial" (FERNANDES, 1975, p.36). Com a independência teria havido uma inversão e o liberalismo teria se transformado na força dinamizadora da sociedade civil. Coube a essa ideologia liberal pós-independência, em um processo de longa duração, transcender e negar a ordem tradicional senhorialescravocrata. Essa transição progressiva para uma ordem social competitiva ocorreria devido à diferenciação social que deu origem a diversos grupos (setores mercantis, profissionais liberais, elite agrária paulista, entre outros), cujos papeis sociais eram incompatíveis com a antiga ordem, pois agiam a partir de um sistema de orientação racional.

Parte da sociedade, portanto, se destacou das estruturas tradicionais e, apesar das condições da persistência da escravidão e do patrimonialismo, "um sistema competitivo pode coexistir e chocar-se com o sistema estamental" (FERNANDES, 1975, p.48). Como o processo que levava à modernização era passivo e de longa duração, a nascente burguesia passou a tirar vantagem da coexistência no Brasil da ordem patrimonial com a orientação racional, ou seja, da convivência do moderno com o atraso.

Em outros termos, o Estado nacional nasce moderno, porém, mantém uma convivência com o patrimonialismo. Foi por meio dessa convivência paradoxal que o país se inseriu no capitalismo mundial. O paradigma dessa ordem contraditória é a convivência, no final do século XIX e início do XX, da agroexportação cafeeira, de orientação racional-competitiva, com o estilo senhorial no campo político: a economia cafeeira não foi capaz de racionalizar a vida política e social. Fernandes (1975) defende que os agentes sociais modernizantes ficaram confinados à esfera privada e acabaram se incorporando aos círculos conservadores e compartilhando as formas de dominação política tradicionais. Deslocando o foco do Estado para a sociedade, o autor defende que a superação do patrimonialismo só poderia ocorrer com a livre manifestação daqueles que viviam sob o estatuto da dependência pessoal que prevalecia na sociedade brasileira. Em síntese, a análise de Fernandes (1975) busca nos fundamentos da formação do Estado demonstrar que os interesses dos novos grupos sociais, muito mais que vinculados à defesa da modernização, buscavam conservar o status quo.

No mesmo diapasão de Fernandes (1975), Franco (1997) se distancia da interpretação que coloca o Estado patrimonial como instância autônoma da sociedade e responsável pelo atraso. Ela defende que a tese weberiana da singularidade estatal da organização burocrática no Ocidente moderno teria que ser adaptada ao contexto brasileiro. A expropriação do servidor público dos meios materiais da administração teria sido no Brasil apenas formal, pois, devido à escassez de recursos do Estado, esses 
meios materiais eram financiados com recursos privados. Indo contra a ideia de uma pretensa natureza Oriental do Estado, Franco credita a fusão não desejada do público com privado à pobreza da agência estatal. Essa fusão do público e do privado teria permitido que o exercício do poder do cargo público ocorresse no sentido de atender a fins particulares. Franco (1997) acaba inscrevendo o patrimonialismo brasileiro como de caráter societal e de raiz agrária.

Vianna (1999) afirma que o patrimonialismo societal, ao contrário do patrimonialismo institucional que compreende o Estado como instância autônoma, percebe o Estado como instrumento. O Estado se baseava nos princípios da burocracia racional-legal, porém, era um instrumento dos senhores de terras para prolongar sua dominação pessoal na vida pública. Desde a formação do Estado no país, combinou-se, de forma ambígua, a dominação racional-legal e a tradicional, essa última derivada do modo de propriedade das relações de trabalho predominantes. Portanto, o elemento retardatário do desenvolvimento brasileiro não estaria no Estado, mas na própria sociedade civil. Para que houvesse a formação de atores sociais autônomos seria necessário erradicar o patrimonialismo societal que fora preservado no processo de modernização e acabar com a capacidade da esfera privada de utilizar a esfera pública em seu benefício. No entanto, a modernização capitalista induzida pelo Estado, a partir da década de 1930, vai reafirmar essa coexistência do atraso e do moderno, uma vez que as elites tradicionais continuaram no poder e a autonomia das camadas populares não se concretizou.

Ainda segundo Vianna (1999), pode-se afirmar que a teoria do patrimonialismo societal se singulariza por compreender que não havia uma contraposição agonística entre atraso e moderno devido ao desenvolvimento desigual do capitalismo brasileiro. Ao contrário, os princípios antitéticos da modernidade e do atraso se acomodavam e se fundiam ecleticamente no Estado. A modernização capitalista que se seguiu à Revolução de 1930, não foi capaz de deslocar do poder as elites tradicionais e promover a livre manifestação da estrutura de classes, logo seria resultante de uma composição heterônoma, que conjugaria princípios tradicionais e modernos, os quais marcaram a formação sociopolítica e institucional brasileira.

O nacional-desenvolvimentismo da Era Vargas e governos seguintes compatibilizaram a modernização econômica com a manutenção das oligarquias tradicionais no poder. A sustentação pluriclassista do regime, no entanto, era uma inovação introduzida por Getúlio Vargas. Através do corporativismo sindical e da legislação trabalhista originária do fascismo italiano, Vargas trouxe à cena política e à ideologia do Estado um novo ator: os trabalhadores do mercado formal. Esse mecanismo de incorporação da classe trabalhadora no mundo da política, no entanto, ceifou a 
possibilidade de desenvolvimento autônomo da classe trabalhadora. Os trabalhadores acabaram se tornando um instrumento para conferir legitimidade ao projeto político do governo que apenas na aparência representava os interesses da coletividade como um todo (FERNANDES, 1975).

A teoria do populismo (WEFFORT, 2003; IANNI, 1968), que busca analisar o período inaugurado por Vargas no Brasil, vai encontrar seu eixo analítico para explicar o Brasil nos conceitos weberianos discutidos acima, apesar da influência ser mais velada que explícita segundo Vianna (1999). O mesmo autor ainda defende que essa teoria não teria percebido a delicada conexão entre o atraso e o moderno, presentes em Fernandes (1975) e Franco (1997), e, teria deslocado a ênfase para o tema da subjetividade ao invés de enfatizar as macroestruturas. Ao contrário do eixo analítico que a inspirou, portanto, a teoria do populismo enfatiza que é por meio da vontade do ator moderno que se afastariam os constrangimentos estruturais que impediam a construção da identidade autônoma do operário brasileiro. De acordo com essa vertente de pensamento, a miséria brasileira poderia ser explicada pelo patrimonialismo privado que impedia o desenvolvimento de uma racionalidade de tipo Ocidental. Tal patrimonialismo se manifestava, por exemplo, na estrutura sindical corporativa e nas coalizões pluriclassistas que uniam elites modernas e tradicionais. Dessa forma, somente com o desenvolvimento de um sindicalismo autônomo seria possível romper com um Estado que mantinha formas tradicionais de controle social. Os sindicatos estruturados de forma racional deveriam se insurgir contra as lideranças carismáticas que negavam sua autonomia e construir uma nova forma de Estado.

É fato que a teoria do populismo se associa aos interesses do trabalhador industrial e da necessidade de romper com sua cooptação por parte do Estado. Sua expectativa era mudar o Estado a partir das fábricas. Segundo Vianna (1999), a teoria do populismo acabava por reforçar a versão weberiana do patrimonialismo de Estado ou institucional, pois se limitava a contrapor a coalizão do moderno com o atrasado que predominava no sistema ao moderno representado pelo operário.

Apesar das diferenças entre as versões weberianas de intepretação do Brasil apresentadas acerca da relação entre Estado e sociedade, do peso conferido por essas versões a cada um desses polos e de uma visão mais ou menos disjuntiva entre eles, é possível, ainda segundo Vianna, encontrar semelhanças entre elas: a indicação da necessidade de uma ruptura com a tradição e a ênfase ao papel negativo do Estado na formação da sociedade brasileira contemporânea. Qual dessas teorias abordadas mais se aproximaria dos insights sobre o patrimonialismo presentes na obra de José de Alencar? Ou haveria no autor uma combinação entre elas? Essas questões serão discutidas nos apartados seguintes. 


\section{Elementos da acomodação entre tradição e modernidade em Senhora}

O final do século XIX no Brasil foi marcado por uma ampla luta em torno de diferentes modelos literários e político-doutrinários. A polêmica José de AlencarJoaquim Nabuco é representativa dessa batalha. Tanto essa polêmica como o texto Senhora oferecem riqueza de detalhes para se pensar a relação entre forma e conteúdo. Em ambos os escritos literários, constata-se a forte tensão entre a construção da narrativa do romance moderno, drama burguês em ascensão no Brasil daquela época, e o adensamento do conteúdo literário, objetivado na complexificação da subjetividade das personagens e no espessamento do entorno sociopolítico-cultural, bases da construção narrativa (COUTINHO, 1965).

A "Polêmica Alencar-Nabuco", que se deu por meio do Jornal $O$ Globo de 3 de outubro de1875 a 21 de novembro de 1875 , num total de 14 artigos, traz contribuições para a compreensão da ampla luta em torno de diferentes modelos literários e políticodoutrinários, observada no final do século XIX no Brasil. A posição central de Alencar, ao longo da polêmica, retomava o debate entre duas concepções político-culturalliterárias ideologicamente contrastantes. De um lado, estava Alencar e os intelectuais românticos na defesa de que o Estado e a tradição eram as formas objetivas de construção de uma sociedade civilizada americana. Dentro desta sociedade não haveria modernização e individualidade efetivamente libertadoras sem a mediação ordenadora do Estado e a universalidade da cultura nacional.

Do outro lado, em contraste com a concepção político-cultural-literária de Alencar, posicionavam-se Nabuco e alguns integrantes da Geração 1870, particularmente, dos "novos liberais" (ALONSO, 2000, p.161), basicamente, formado por indivíduos nascidos de famílias tradicionais do Império obstruídas politicamente e em processo de empobrecimento econômico. Entretanto, os seus capitais políticos e econômicos guardavam bons níveis de integridade. Figurariam entre os seus integrantes os intelectuais Joaquim Nabuco, André Rebouças, Rui Barbosa, Rodolfo Dantas, Muniz Barreto, Barros Pimentel, José Mariano Carneiro da Cunha e Gusmão Lobo dentre outros. Eles demandavam por um projeto político que pressionava pela abolição da escravidão e pela modernização econômica do país. A escravidão era entendida como o obstáculo estrutural maior ao surgimento de um país economicamente viável, ao não permitir a formação de um mercado com a força de trabalho livre e a ampliação do mercado de bens de consumo (ALONSO, 2000). No entender de Nabuco e dos novos liberais, a proposta de Alencar de extinção da escravidão, sequenciada no ritmo da 
"revolução dos costumes", seria o resumo e a prova de que a inércia política e social não liquidariam "um regime que, há três séculos, é uma escola de desmoralização e inércia, de servilismo e irresponsabilidade para a casta dos senhores" (NABUCO, 2003, p.27).

Por sua vez, o texto Senhora dá testemunho da tensa acomodação entre forma e conteúdo e do conflito entre dois projetos literários e político-doutrinários: modelo memória-tradição versus modelo de civilização e modernização da nação pela abertura à Europa saxônica e francesa. O rebatimento do conflito entre os dois modelos reverbera no romance Senhora, precisamente, no intenso esforço de construção do romance em quatro capítulos, O preço, Quitação, Posse e Resgate, cujo eixo central consiste nas relações econômicas desdobradas, por um lado, na subjetividade dos personagens, dilacerada e fragmentada. Contudo, de outro lado, Alencar avança no desfecho do romance, contraditoriamente, de modo a fazer com que as relações econômicas sejam subsumidas e superadas pelo amor, pela honra, pelo trabalho e pela disciplina.

A narrativa do romance ganha alguns contornos do projeto político de Alencar, em particular, da sua resistência ao surgimento do indivíduo burguês e à instauração das relações de troca burguesas e à ação dos novos grupos sociais e políticos pela ampliação dos direitos civis e modernização da nação. Nestes termos, o autor de Senhora hostilizava a modernidade, reagia às pressões políticas dos novos grupos sociais e combatia a introdução entre nós das novas conquistas técnico-científicas europeias, tudo isto em nome da manutenção e restauração de uma sociedade de privilégios aristocráticos. A seu ver, somente sob os filtros da tradição-memória nacional era possível realizar a promessa de construção de uma civilização nos trópicos.

Dentro do seu diagnóstico, o universo das relações burguesas, onde se encontravam Aurélia e Fernando Seixas, amesquinhava os indivíduos, rebaixava os sujeitos moralmente, esvaziava os significados socioculturais fundados na tradição e memória nacionais e instrumentalizava as relações dos indivíduos com os outros e consigo mesmos. O projeto político de Alencar, fundamentalmente, concebe que as formas sociais e políticas aristocratas são estáveis e formadoras de um ethos social necessariamente emancipador do gênero humano e capaz de dirimir todas as diferenças de classe e visões de mundo, o que contrasta frontalmente com a modernidade.

Aurélia Camargo e Fernando Seixas constituem as personagens principais do romance. Ela nascera de um jovem pai (Pedro Camargo), o qual por sua vez era filho de um rico senhor de terras (o velho Camargo). Enquanto a mãe de Aurélia (Emília Camargo) era nascida sob o signo da pobreza, que se tornou ainda mais aguda quando Emília precisou arcar sozinha com a criação da filha, depois de Pedro Camargo a abandonar por pressão do pai e, passados alguns meses, vir ele a falecer ainda muito 
jovem.

Fernando Seixas era filho de um funcionário público de cargo mediano. A morte prematura do pai impôs a Fernando interromper os seus estudos na Faculdade de Direito de São Paulo quando aí cursava o $3^{\circ}$ ano, pois "o pai deixara o escasso patrimônio complicado com uma hipoteca, além de várias dívidas miúdas" (ALENCAR, 1977, p.34). Assim, a morte do pai rebaixou ainda mais o padrão econômico e social da família Seixas. O caçula Fernando Seixas passou de estudante a funcionário público. Por sua vez, a mãe juntamente com as duas irmãs tornaram-se costureiras. Contudo, nem no longo prazo, o trabalho das mulheres e a posse do cargo público de função menor exercido por Fernando Seixas foram capazes de elevar o padrão econômico e social da família, ou mesmo repô-lo nos patamares em que se encontrava quando o pai ainda era vivo. A vida da família Seixas seguia o modelo usual daquelas famílias na luta pela sobrevivência, cuja dinâmica tornava-se ainda mais mal tratadora da integridade psíquica das mulheres. Isto porque o trabalho feminino era retribuído sempre em níveis de valor rebaixados em comparação ao trabalho dos homens (MICELI, 2001).

No plano afetivo, as perdas não eram menores: nem festas e nem passeios pelas ruas do Rio de Janeiro; as filhas envelhecendo sem ao menos conhecer outra intimidade senão a delas próprias; o trabalho tomando para si cada vez mais a afetividade e até mesmo o pouco tempo qualitativamente bom para cuidar de si. O mundo das mulheres da família Seixas comprimia-se ao peso do imperativo do trabalho de subsistência, estendido no "serão na sala de jantar, em volta do candeeiro, que alumiava a tarefa noturna. O mais das vezes solitárias; outras acompanhadas de alguma rara visita, que as frequentava no seu modesto e recatado viver" (ALENCAR, 1977, p.35).

Cada vez mais tolhidas pelo trabalho ao preço do sacrifício dos afetos, as carentes irmãs Seixas tomavam os relatos amorosos e as confidências do irmão Fernando como o tema das suas conjunturas. Às confidências do irmão, elas misturavam as suas orações pelo seu sucesso em alguma das suas alardeadas investidas amorosas: talvez daí resultasse um casamento com uma moça de família rica. Tão reduzido ficara o universo das mulheres da família Seixas que o plano do filho de levá-las a uma apresentação lírica tornou-se para ele motivo de vergonha e preocupação.

A modéstia e a simplicidade no vestir, tanto da mãe como das irmãs, eram traduzidas pelo olhar severo em pontos da elegância, como um "vestuário esquisito" de três mulheres "alheias às modas e usos da sociedade". O vestuário das irmãs e da mãe fez com que Fernando perdesse o chão e relutasse em voltar ao camarote da família, depois da observação sarcástica de um amigo no meio daquela noite de apresentação: “- Ó Seixas, não me dirás onde foste desencovar aquele terno de roceiras? (...) Que temível!” (ALENCAR, 1977, p.37). 
De fato, o mundo daquelas mulheres era construído em cima de interesses, hábitos e expectativas em muitos aspectos diferentes daqueles hábitos urbanos e refinamentos europeizados, cultivados entre os grupos sociais fartos e bem-instalados da Corte. As mulheres da família Seixas viviam um cotidiano de regularidades quase rural. As irmãs, ainda que iniciadas no trabalho da costura, atendiam a pessoas simples e remediadas, como elas mesmas, nascidas na Rua do Hospício. De sorte que desconheciam as sofisticações e os requintes da moda consumida pela alta classe da Corte.

Ao longo do romance, o narrador trabalhou no sentido de estilizar o mundo dos indivíduos medianos e pobres como altamente previsível, ordeiro, ajustado e tradicional. Vez ou outra toda esta regularidade era quebrada com os jogos de sedução do tio Lemos sobre a sobrinha, que naquele momento estava fragilizada com a morte do irmão e com o agravamento da saúde da mãe, que veio também a falecer deixando assim Aurélia órfã e ainda mais pobre. Neste mundo moralista e encontradiço, o narrador não deixou de fora o cinismo e o interesse escuso da "gente de condição inferior" ao redor de Aurélia: num primeiro momento, tão folgada no juízo de que a mãe de Aurélia era uma "mulher perdida" e merecedora de se evitar o "contágio de sua reputação". Posteriormente, transmutou-se este "juízo endireitador” (ALENCAR, 1977, p.93), em atitude de servilismo e bajulação, quando Aurélia foi agraciada, de um dia para outro, com uma rica herança do avô paterno.

Consequente com as suas ideias de preservar os homens pobres e interioranos, o narrador ameniza a vileza de Lemos e de Firmina, na conquista de alguns réis a mais ilicitamente, como atitudes aceitáveis. Pois partiam de indivíduos que tinham as suas vidas estacionadas no limiar da extrema pobreza. Em outro momento do romance, a vida de privações e de trabalhos das mulheres da família Seixas contrastava com a existência do irmão Fernando. Era uma existência alardeada nos salões e salas de espetáculos da Corte e muito destoante do modo de viver rígido das mulheres.

Basta elencar alguns dos hábitos europeizados, cultivados na Corte, que foram incorporados por Fernando Seixas: o chapéu "chaque do melhor fabricante de Paris"; o corte elegante e esmerado definido na "casaca preta" pelo alfaiate da moda Raunier; as luvas de "jouvin cor de palha"; a botina confeccionada pelo primeiro fabricante de sapatos de pelica no Brasil, o sapateiro francês "Campas"; o hábito de fumar "charutos de Havana"; "no toucador de um rapaz à moda (...) as mais finas essências francesas e inglesas (...) das casas do Bernardo e do Louis" (ALENCAR, 1977, p.29-30).

Diante do descompasso entre os dois estilos de vida e do peso desigual da distribuição das obrigações domésticas, acrescidas da luta pela sobrevivência e das exigências morais impostas às mulheres nascidas nos estratos sociais pobres, o narrador 
sem usar de qualquer ironia reduzia o seu juízo a determinações moralizantes e tradicionalistas. Por exemplo, na avaliação de Alencar, os novos hábitos importados da Europa representavam um perigo à integridade da família brasileira. A solução por ele proposta seria recorrer à única força social capaz de resistir-lhes: "A vigorosa educação (...) a antiga educação brasileira, já bem rara em nossos dias, que, se não fazia donzelas românticas, preparava a mulher para as sublimes abnegações que protegem a família e fazem da humilde casa um santuário" (ALENCAR, 1977, p.35).

A trama do romance Senhora opera entre dois universos narrativos. De um lado, encontram-se ambientes onde se preservava os traços de uma sociedade eticamente exemplar, enquanto reflexo da "adesão emocional à tradição, à história e aos costumes", apontada por Ângela Alonso como o fundamento do projeto de civilização alencariano (ALONSO, 2000, p.148). Do outro lado, estava se formando um mundo em que a cultura era mais cosmopolita, os hábitos europeizados e as relações sociais cada vez mais regidas pela forma dinheiro. Em suma, um mundo pelo qual Alencar manifestava as mais fortes resistências.

Neste universo de relações sociais emprestadas ao econômico, o narrador introduziria a personagem Fernando Seixas que lançou mão do casamento como estratégia de ascensão econômica, ao aceitar um dote de cem contos. Este casamento era parte do plano de vingança de Aurélia, motivada pelo fato de Seixas a ter preterido por outra mulher de melhor condição econômica, quando ela era ainda uma órfã pobre.

De certa forma, Fernando Seixas ajustava-se ao drama alencariano presente em alguns dos seus romances, nos quais se discutia as formas de ascensão social dos jovens bacharéis ou moços: todos muito talentosos, todavia pobres. Neste sentido, tem-se como exemplos Augusto Amaral em Diva (1856); Leopoldo de Castro em A pata da gazela (1870); Ricardo em Sonhos d'Ouro (1872a) e Mário em Til (1872b). Nestes romances, Alencar acomodou com solicitude os seus casamentos por meio da construção de muitos lances de amor, de tal forma a minorar a acusação de interesse (MIGUEL-PEREIRA, 1994).

A ascensão social destas personagens principais foi feita pela via do casamento, ao se unirem a mulheres ricas, filhas de endinheirados fazendeiros e comerciantes. Por sinal, esses eram os únicos grupos sociais na sua ficção em que os indivíduos se enriqueceram pelo trabalho e os dois únicos estratos sociais, tidos por Alencar, em conta de grupos sociais economicamente sólidos. A ausência na ficção de Alencar dos grupos sociais ligados às profissões liberais traduzia os aspectos de uma sociedade patrimonialista em que as relações sociais ainda estavam pouco reificadas. Bem como traduzia as resistências de um narrador ainda pouco afeito a admitir os processos de objetivação da forma dinheiro, "cada vez mais planificada nas organizações sociais e 
nos impulsos dos indivíduos" (SCHWARZ, 2000, p.55).

Contudo, havia outros heróis dos romances urbanos de Alencar que eram jovens talentosos, ricos, elegantes, educados, mundanos e regiam-se pela observância estrita das regras do bom-tom. Entretanto, eram em geral homens de vida ociosa, dedicados a nada fazer e nunca se portavam como empreendedores. Por exemplo, no romance $A$ viuvinha e cinco minutos (1924), o narrador era um jovem pouco atarefado que viajou à Europa em busca da amada. Depois de retornado à Corte, ele andava desocupado a "passear pela Rua do Ouvidor e a ouvir falar de política e teatro". No romance não se sabe sequer qual a profissão de Jorge. Salvo que era o filho de um falecido negociante rico que vivia a "gastar o dinheiro que seus pais ganharam" (ALENCAR, 1924, p.2). O herói cortejado das mulheres Hermano de Aguiar do romance Encarnação (1938, p.3), segundo a própria informação do narrador, vivia uma vida de aristocrata "não se lhe conhecia [a] profissão; sabia-se, entretanto, que era abastado, pois além da chácara de sua residência, possuía apólices e prédios na cidade".

Indivíduos empreendedores e enriquecidos por meio do trabalho não estavam ausentes do universo narrativo de Alencar. João Barbalho, personagem de Sonhos D'Ouro, "começara a vida como tocador de tropa". Conjugando arrojo e tino para os negócios, "em uma de suas viagens à corte arrumou-se como caixeiro no armazém de mantimentos do consignatário". Tornando-se assim, aos cinquenta anos, um bemsucedido comerciante "possuidor de algumas centenas de contos" (ALENCAR, 1872a, p.47). Quando de todo rico e bem-sucedido, João Barbalho sentiu-se atraído pelos títulos nobiliárquicos e convencendo-se de que não era de bom-tom um rico capitalista ser tratado como tropeiro comprou o título de Barão do Saí: "trocou por um título à-toa aquele nome que valia um brasão; fidalgo brasão, se já o houve, pois era o do trabalho e perseverança, e tinha por timbre e divisa a probidade" (ALENCAR, 1872a, p.47). A compra do título nobiliárquico por João Barbalho revela o conflito instaurado sobre os grupos sociais estratégicos, inseridos numa sociedade em transição que conjugava ordens sociais e econômicas contraditórias.

A ordem burguesa e a ordem estamental patrimonialista conviviam numa perversa simbiose, refundidas em instituições políticas e sociais Imperiais, por meio da perpetuação da lógica do favor e da prebendalização de cargos e postos públicos. Isto graças ao apoio de grupos sociais ligados à economia agrário-escravista e à elite político-burocrática.

As personagens Fernando Seixas e Aurélia retomam alguns elementos do embate entre essas duas formas de configuração social. Na medida em que os seus conflitos articulam-se dentro da oposição entre o ethos estamental dos senhores rurais e o ethos burguês. Fernando Seixas, antes do casamento com Aurélia, vivia segundo um 
estilo de vida aristocrático. Daí se impor coerções no sentido de assegurar prestígio e posição de relevância em eventos sociais, os quais ele tomava como deveres e exigências sociais.

No empenho de manter prestígio e autoafirmação social, Fernando Seixas gastava todo o seu vencimento mensal, ganho como funcionário público, e mais outro tanto retirado da poupança acumulada pela família, cuja administração do capital estava sob a sua guarda. Assim, enquanto as mulheres sobreviviam com $150 \$ 000$ mensais, Seixas queimava mensalmente 6:700\$000, "quantia que naquele tempo não gastava com a sua pessoa muitos celibatários ricos, que faziam figura na sociedade da corte" (ALENCAR, 1977, p.36). Ligando-se à alta roda social por meio de festas, jantares, bailes, idas ao teatro e namoricos, Seixas operava segundo comportamento e mentalidade aristocrática, transferindo toda a sua afetividade, inteligência e vontade à expectativa de retribuição de amizades. Acima de tudo, alimentava a esperança de se dar bem por meio de um casamento bem-sucedido.

Conquistado o casamento com a rica herdeira Aurélia, Seixas seria treinado em formas sociais distintas da anterior. Ele passaria a ser treinado na mentalidade burguesa. De certa forma, no ciclo de formação do Seixas burguês, não havia a gravidade da motivação do indivíduo pela valorização do cumprimento do dever, associado à realização de alguma vocação profissional ou eleição divina: "elementos capazes de imporem-se como autorrealização moral mais abrangente e sistêmica de um modo de vida metodicamente construído" (SCHWARZ, 2000, p.59).

O empenho no aprendizado da acumulação e a motivação em treinar-se na capacidade de perceber as oportunidades econômicas de reprodução do capital, surgidas no seu cotidiano, mobilizavam a vontade e o entendimento de Seixas. Inicialmente, como reação ao cálculo de vingança colocado em prática por Aurélia de fazê-lo assinar um documento no qual reconhecia a dívida de cem contos referente ao dote.

De fato, a forma como se deu o casamento constituiu um negócio, pois foi feita por meio de um procurador que propôs a Seixas um dote de cem contos sem que ele conhecesse a mulher com quem iria se casar. Assinado o documento, Seixas foi apresentado à Aurélia, a qual não só exigiu a realização do casamento como ainda fez com que Seixas fosse morar com ela no seu palacete. Morando juntos, Aurélia deu vazão aos seus sentimentos sádicos de pungi-lo com o seu mais virulento sarcasmo, num nível tal de provocação que fez com que Seixas quase sucumbisse à vergonha e à degradação. Tratado publicamente como adereço e acessório da Senhora nos círculos frequentados pela boa sociedade da Corte, Seixas tomou a decisão de dar fim à sua condição de homem vendido e escravo branco, determinando-se a comprar a sua alforria (SCHWARZ, 2000). 
Neste sentido, ele passou a obrigar-se à contenção dos seus gastos; recusou a aceitar qualquer dinheiro ou presentes dados por Aurélia; e procurou aprender dela a condução dos negócios com a gelidez do argumento, a perspicácia e o perfeito conhecimento que mostrava dos negócios. Neste processo de autocorreção transformadora, Seixas interiorizou de tal forma a disciplina do trabalho que se antes ele consumia o tempo na repartição pública "na palestra e no fumatório" (ALENCAR, 1977, p.118), ele passou então à condição de funcionário público exemplar: assíduo e pontual. Tamanhas foram as transformações nele operadas que os colegas da repartição pública perceberam as mudanças na sua natureza íntima transbordarem-se nos seus gestos: "mudança notava-se em Seixas. Era a gravidade (...) ainda seus lábios se ornavam de um sorriso frequente; mas ele trazia o reflexo da meditação e não era como dantes um sestro de galanteria" (ALENCAR, 1977, p.118).

Aos poucos o estilo de vida de Fernando Seixas foi formando um conjunto mais coeso e coerente de atitudes interiores e de condutas de vida metodicamente construídas, voltadas à reprodução da forma dinheiro, as quais, por sua vez, penetravam cada vez mais na sua existência inteira. Elas se tornaram tão imperativas e estimulantes à autoinspeção contínua que a regulamentação planificada da vida pessoal de Seixas transformou-o num homem insensível "nem bom, nem mau. Nem digno de ser amado; nem tão vil, que lhe evite o contágio" (ALENCAR, 1977, p.128). Mesmo para Aurélia, por sinal, já bem avançada na condução da sua vida segundo a ética burguesa, Seixas era "um desses homens equívocos, produtos da sociedade moderna" (ALENCAR, 1977, p.128). O trabalho de iniciação de Seixas no universo burguês, começado nas mãos de Aurélia, resultou na formação de um indivíduo cada vez mais sofisticado na conduta consentida de consecução do ethos burguês. Daí o sentimento asfixiante, por trás do relato de Aurélia, acerca de Seixas:

Não me importaria que ele fosse Lúcifer, contanto que tivesse o poder de iludirme até o fim, e convencer-me de sua paixão e inebriar-me dela. Mas adorar um ídolo para vê-lo a todo o instante transformar-se em uma coisa que nos escarnece e nos repele. (...). É um suplício de Tântalo. (ALENCAR, 1977, p.128-129).

Neste aspecto, o desabafo de Aurélia condensava toda a resistência do narrador Alencar ao avanço da ordem burguesa sobre a ordem patrimonialista. Nesta última ordem, Alencar projetava toda a sua esperança de realização da eticidade e de emancipação do homem dos trópicos, traduzida em termos científicos, na sua resistência aos elementos positivos e utilitários; e, nos termos políticos, na manutenção dos privilégios aristocráticos. 
No romance Senhora, Alencar questiona a unidade interior e coerente dos personagens, rebaixando-os pelo irreverente amoralismo. Contudo, policiava-se, ponderava e interrompia os processos narrativos de destrato das criaturas ficcionais ao procurar ajustá-las e reabilitá-las pelo sentimento reparador do amor, quase descabido em personagens tão amesquinhados. Alencar deixaria a Machado de Assis dar o passo mais além e mais elaborado no sentido de amesquinhar as criaturas ficcionais, ao tornálas mutáveis, amorais e cínicas (CANDIDO, 1975; SCHWARZ, 2000).

\section{Conclusão: os insights de Alencar acerca da acomodação tensa entre o patrimonialismo e a modernidade}

Alencar resistia à modernidade representada pela nova ordem racional burguesa quando procurava reconstruir nostalgicamente a unidade perdida entre norma e tradição. Neste sentido, havia a patente atitude intelectual e afetiva da sua parte de sugerir, como meio de superação da dissolução do ethos aristocrático dos senhores rurais, formas de conhecimento que não fossem unicamente centradas no saber formalista racional. Como, por exemplo, o respeito à sensação (CARVALHO, 1998). Essa seria uma forma de saber estruturada na íntima relação entre a natureza e a tradição, instituída sob valores comumente aceitos por uma sociedade específica. De certo modo, Alencar propunha outra forma de estar e conduzir-se no mundo que não aquela imposta pelo conhecimento formalista racional, "cujo desdobramento estaria levando à criação do indivíduo burguês, coisificado nas suas relações com o mundo e consigo mesmo" (BOSI, 1979, p.153).

Alencar demonstrou a negatividade do universo da troca em crescente consolidação no Segundo Reinado por meio do processo narrativo. E fez isto com muita propriedade ao levar o leitor a conscientizar-se de que as existências dilaceradas e sofridas de Seixas e Aurélia decorriam da instrumentalização das relações sociais e das relações do indivíduo consigo mesmo em razão do imperativo da forma dinheiro. Se, por um lado, o desapreço de Alencar pelo avanço das formas objetivas do capitalismo e do modo de vida burguês apoiava-se na sua crítica à fragmentação e instrumentalização dos indivíduos, por outro lado, Alencar aderia por demais ao estilo de vida de grupos sociais aristocráticos, cuja condução e a tomada de decisões políticas estavam restritas a uma confraria.

Neste sentido, o projeto político festejado pelo próprio Alencar, em discurso na Câmara quando assumiu o cargo de Chefe de Estado (Ministro da Justiça), por ele intitulado de aurora da regeneração, propunha o exercício de um governo pessoal forte 
por parte do Imperador e a manutenção da restrição do acesso à tomada de decisões dos rumos políticos da nação. Era uma tese na direção contrária da proposta política de abertura dos processos políticos, defendida por Joaquim Nabuco e representantes dos grupos sociais emergentes.

Consequente com a sua atitude de resistência à expansão da participação política dos novos grupos sociais, o romance Senhora, apesar de escrito em 1875, não inclui entre as suas personagens os profissionais liberais e nem os considera como integrantes dos grupos sociais estratégicos e endinheirados. Além do mais, reproduz com certa fidelidade o lugar a ser ocupado pelos escravos e homens livres pobres na sociedade do Segundo Reinado: no exercício dos serviços domésticos e ocupações manuais de toda ordem. Neste aspecto, ao longo do romance, eles nunca são chamados pelo nome. Estes indivíduos são gente às quais a senhora se dirigia somente para dar ordens.

Em sua imersão mimética, José de Alencar intuiu em Senhora os elementos da tensa acomodação entre a nascente ordem racional-legal e a ordem patrimonialista no período imperial brasileiro, ao mesmo tempo em que demonstrou sua contrariedade com o avanço da nova ordem burguesa. Tendo como referência as teses sobre a aclimatação do romance europeu de cunho realista no Brasil de Roberto Schwarz (2000), um dos principais interlocutores da obra de Alencar, é possível identificar os insights do romancista acerca do mimetismo entre o atrasado e o moderno no país, os quais o presente artigo faz referência.

Embora de forma não declarada, o pensamento de Schwarz (2000) se filie à vertente de interpretação denominada patrimonialismo societal (FERNANDES, 1975; FRANCO, 1997), como descrito anteriormente nesse artigo, o que distingue as interpretações weberianas do Brasil são as questões concernentes à relação entre Estado e sociedade, ao peso conferido a cada um desses polos e a visão mais ou menos disjuntiva entre eles. Enquanto o patrimonialismo institucional (FAORO, 1975; SCHWARTZMAN, 1998) e as teorias do populismo (WEFFORT, 2003; IANNI, 1968) se aproximam ao conceder uma relativa autonomia a um Estado que se impunha à sociedade, o patrimonialismo societal atribui à dinâmica social um tipo próprio de dominação que é refletida na esfera pública e é por essa influenciada.

A crítica de Schwarz (2000) à obra de Alencar aponta para ausência de uma força artística, apesar do seu acerto na força mimética. Ou seja, apesar dos problemas de composição do drama, que estão "sempre aquém do nível que só a coerência artística dá" (SCHWARZ, 2000, p.65), o romance possuiria uma "garra mimética" (SCHWARZ, 2000, p.67). Há em Senhora, segundo o crítico, um contrassenso: a seriedade da temática que impulsiona o enredo - a compra de um marido, o poder do dinheiro e do 
sexo, o cálculo racional das ações - torna latente a forma europeia do romance, por outro lado, existe um desejo patriótico do autor de descrever o Brasil. Esse dever de escrever sobre a pátria, à qual Alencar se dedica, faz com que ele crie personagens periféricos e histórias secundárias que desdramatizam o enredo. O rigor, moralismo e a seriedade da narrativa do romance convencional europeu cedem lugar ao humor dos acontecimentos cotidianos e a personagens bonachões característicos da vida social brasileira pelos quais o romancista nutria simpatia.

Ao tentar traduzir o Brasil na forma do romance europeu, o resultado é um conjunto de contradições. A racionalidade burguesa de Aurélia, por exemplo, convive com personagens periféricas regidas pelo favor. Essas esferas não aparecem em conflito e também não são criticadas por Alencar, isso porque ele é um admirador tanto da sofisticação europeia quanto do jeito brasileiro de ser. Essas ordens conviveriam provocando a fraqueza artística à qual Schwarz (2000) se refere.

Em Alencar, no entanto, a prática do favor apenas permeia a obra tomando um aspecto periférico. Ao colocar o núcleo moderno - dinheiro versus amor - em primeiro plano se descuidando das relações paternalistas e do favor, o romancista teria tornado a temática europeia mais relevante que o patrimonialismo societário. Será somente na segunda fase da obra de Machado de Assis que, segundo Schwarz (2000), ocorrerá uma inversão da importância dada a esses elementos. Ali, o favor passa a predominar sobre as ideias e modas europeias retratando a verdadeira realidade oitocentista brasileira.

Em Senhora ocorre apenas uma justaposição entre as ordens racional-legal e a patrimonialista no plano formal mantendo uma disjunção entre elas, e essa é a grande crítica que se pode fazer ao autor. Alencar parece não perceber plenamente a "unidade contraditória" (FRANCO, 1997, p.11) eivada de tensões entre essas esferas. Essa disjunção entre as duas ordens presente na obra pode levar a uma ideia de declínio da ordem tradicional que estaria sendo substituída por uma ordem moderna, ao contrário do que é defendido pela teoria do patrimonialismo societal que defende uma imbricação dialética entre elas. Tal crítica, no entanto, não impede o reconhecimento de que a força de Senhora está em seu aspecto mimético. É na explicitação da convivência entre os núcleos dinâmicos da vida social baseadas no favor e no lucro que podem ser encontrados os insights que demonstram a difícil acomodação entre o moderno e o atrasado no Brasil.

A obra de Alencar permite a confrontação com situações e valores imagináveis que apontam para as possibilidades de um mundo social diferente. Ao longo do texto é construída uma realidade ficcional na linguagem a partir do mundo real como um "espelho unidirecional (two way mirror)" (LEENHARDT, 2018, p.38): transparente e refletor ao mesmo tempo, esse espelho possui um discurso de múltiplas facetas onde a 
realidade se mistura com mundos imaginários que pertencem ao escritor e ao leitor. Os grandes textos ficcionais implicam em algum grau de imersão mimética, portanto, mesmo não possuindo uma característica denotativa, a ficção produz conhecimento.

No contexto político do Brasil Império, Senhora oferece aportes significativos para se pensar a tensa acomodação entre patrimonialismo e ordem racional-legal, liberalismo e escravidão, clientelismo e favor; contrastados, com o processo de burocratização e as iniciativas de modernização da Administração Pública. Por meio dos personagens e enredo de Senhora, Alencar intui esse hibridismo entre o tradicional e o moderno na sociedade brasileira da época e deixa pungente sua oposição ao avanço do utilitarismo burguês sobre a ordem patrimonialista, essa última vista como espaço de eticidade e emancipação humana.

\section{JOSÉ DE ALENCAR: INSIGHTS INTO THE TENSE ACCOMMODATION BETWEEN TRADITION AND MODERNITY IN BRAZIL}

ABSTRACT: This paper analyzes the tense accommodation between patrimonialism and bureaucratic capitalist model in the late nineteenth century in Brazil, based on the insights contained in the book Senhora (1875) by José de Alencar. At first, the article analyzes the interpretations of Brazil from Weberian perspective, and then, discuss the process of accommodation between tradition and modernity in the historical context of the Brazilian Empire contained in this work of the novelist. The hypothesis which guides the text is based on the idea that patrimonialism, present in Brazil since the colonial period, reached the peak of its influence and also a process of accommodation with the rational-legal order during the Empire. José de Alencar would portray on the characters and in the plot of this work both the elements of this accommodation and his personal opposition to the advancement of the bourgeois order over the patrimonial order.

KEYWORDS: José de Alencar. Patrimonialism. Bureaucratic capitalist model. Accommodation.

\section{José de alencar: Percepciones sobre el tenso aCUerdo ENTRE TRADICIÓN Y MODERNIDAD EN BRASIL}

RESUMEN: El presente trabajo analiza la acomodación de las tensiones entre el 
fenómeno patrimonialista y el modelo burocrático-capitalista de finales del siglo XIX en Brasil a partir de las reflexiones contenidas en la obra Senhora (1875) de José de Alencar. En un primer momento, el artículo analiza las interpretaciones de Brasil en una perspectiva weberiana y luego discute el proceso de acomodación entre la tradición y la modernidad en el contexto histórico del Imperio brasileño contenido en esta obra del novelista. La hipótesis que guía el texto se basa en la idea de que el patrimonialismo, presente en Brasil desde el periodo colonial, alcanzó el ápice de su influencia y también un elaborado proceso de acomodación con el orden racional-legal durante el Imperio. José de Alencar retrataría en los personajes y en la trama de la obra mencionada los elementos de esta acomodación y su oposición al avance del orden burgués sobre el orden patrimonialista.

PALABRAS CLAVE: José de Alencar. Patrimonialismo. Modelo burocráticocapitalista. Alojamiento.

\section{Agradecimentos}

Os autores agradecem à Fundação de Amparo à Pesquisa do Estado de Minas Gerais (Fapemig) e à Fundação João Pinheiro de Minas Gerais pelo apoio à pesquisa realizada.

\section{REFERÊNCIAS}

ALENCAR, José. Senhora. 8 ed. São Paulo: Editora Ática, 1977.

ALENCAR, José. Encarnação. Rio de Janeiro: Ediouro, 1938. Disponível em: http://www. literaturabrasileira.ufsc.br/arquivos/texto/0006-01153.html. Acesso em: 17 out. 2008.

ALENCAR, José. A viuvinha e cinco minutos. Rio de Janeiro: Garnier, 1924. Disponível em: http://www.literaturabrasileira.ufsc.br/arquivos/texto/0006-00702.html. Acesso em: 17 out. 2008 .

ALENCAR, José. Sonhos d'Ouro. Rio de Janeiro: B. L. Garnier. 1872a. Disponível em: http://www.literaturabrasileira.ufsc.br/arquivos/texto/0006-01229.html. Acesso em: 17 out. 2008.

ALENCAR, José. Til. 1872b. LITERATURA BRASILEIRA. Textos literários em meio eletrônico. Disponível em: https://www.literaturabrasileira.ufsc.br/documentos/?action= download\&id=90891. Acesso em: 03 out. 2020. 
ALENCAR, José. Diva. (1856). LITERATURA BRASILEIRA. Textos literários em meio eletrônico. Disponível em: https://www.literaturabrasileira.ufsc.br/documentos/?action= download\&id=117424. Acesso em: 03 out. 2020.

ALENCAR, José. A pata da gazela (1870). LITERATURA BRASILEIRA. Textos literários em meio eletrônico. Disponível em: https://www.literaturabrasileira.ufsc.br/documentos/ ?action=download\&id=118565. Acesso em 03 out. 2020.

ALONSO, Angela. Ideias em movimento. Tese (Doutorado em Sociologia). São Paulo. Faculdade de Filosofia Ciências e Letras/ FFLCH/USP-SP, 2000.

BOSI, Alfredo. História concisa da literatura brasileira. 2 ed. São Paulo: Cultrix, 1979.

CAMPANTE, Rubens Goyatá. O Patrimonialismo em Faoro e Weber e a Sociologia Brasileira. DADOS - Revista de Ciências Sociais, Rio de Janeiro, v. 46, n.1, p.153-193, 2003.

CANDIDO, Antonio. A formação da literatura brasileira. 5 ed. São Paulo: EDUSP, 1975.

CARVALHO, Maria Alice Rezende de. O quinto século: André Rebouças e a construção do Brasil. Rio de Janeiro: IUPERJ, 1998.

COUTINHO, Afrânio. A Polêmica Alencar-Nabuco. Rio de Janeiro: Tempo Brasileiro, 1965.

COUTO, Elvis Paulo. As Raízes do Patrimonialismo de Estado no Brasil. Revista Habitus.

Rio de Janeiro, v. 14, n. 1, p.100-112, 10 de nov. 2016.

FAORO, Raimundo. Os Donos do Poder. São Paulo: EDUSP, 1975.

FERNANDES, Florestan. A Revolução Burguesa no Brasil: ensaio de interpretação sociológica. Rio de Janeiro: Zahar, 1975.

FRANCO, Maria Silvia de Carvalho. Homens Livres na Ordem Escravocrata. São Paulo: UNESP, 1997.

HOLANDA, Sérgio Buarque de. Raízes do Brasil. 9. ed. Rio de Janeiro: José Olympio, 1976.

IANNI, Octavio. O colapso do populismo no Brasil. Rio de Janeiro: Civilização Brasileira, 1968.

LEENHARDT, Jacques. Existência e objeto da "sociologia da literatura", hoje. Revista Sociologias, Porto Alegre, ano 20, n. 48, p.36-46, maio-ago. 2018.

MICELI, Sérgio. Intelectuais à brasileira. São Paulo: Companhia das Letras, 2001.

MIGUEL-PEREIRA, Lúcia. Escritos da maturidade: seleta de textos publicados em 
periódicos. Rio de Janeiro: Graphia, 1994.

NABUCO, Joaquim. O Abolicionismo. Brasília: Senado Federal, Conselho Editorial, 2003. SCHWARTZMAN, Simon. Bases do Autoritarismo Brasileiro. Rio de Janeiro: Campus, 1998.

SCHWARZ, Roberto. Ao vencedor as batatas. São Paulo: Editora 34, 2000.

SODRÉ, Nelson Werneck. História da literatura brasileira. 4 ed. Rio de Janeiro: Civilização Brasileira, 1964.

VIANNA, Luiz Werneck. Weber e a Interpretação do Brasil. Novos Estudos Cebrap, n. 53, p.33-47, 1999.

WEFFORT, Francisco C. O Populismo na Política Brasileira. 5 ed. Rio de Janeiro: Paz e Terra, 2003.

Recebido em 05/04/2019.

Aprovado em 25/08/2020. 